University of Nebraska - Lincoln

DigitalCommons@University of Nebraska - Lincoln

USDA National Wildlife Research Center - Staff Publications
U.S. Department of Agriculture: Animal and Plant Health Inspection Service

2014

\title{
Synergistic effect of an ultraviolet feeding cue for an avianrepellent and protection of agricultural crops
}

\author{
Scott J. Werner \\ United States Department of Agriculture, scott.j.werner@aphis.usda.gov \\ Shelagh T. DeLiberto \\ USDA/APHIS/WS National Wildlife Research Center, shelagh.t.deliberto@usda.gov \\ Susan E. Pettit \\ United States Department of Agriculture
}

Anna M. Mangan

United States Department of Agriculture

Follow this and additional works at: https://digitalcommons.unl.edu/icwdm_usdanwrc

Part of the Life Sciences Commons

Werner, Scott J.; DeLiberto, Shelagh T.; Pettit, Susan E.; and Mangan, Anna M., "Synergistic effect of an ultraviolet feeding cue for an avianrepellent and protection of agricultural crops" (2014). USDA National Wildlife Research Center - Staff Publications. 1598.

https://digitalcommons.unl.edu/icwdm_usdanwrc/1598

This Article is brought to you for free and open access by the U.S. Department of Agriculture: Animal and Plant Health Inspection Service at DigitalCommons@University of Nebraska - Lincoln. It has been accepted for inclusion in USDA National Wildlife Research Center - Staff Publications by an authorized administrator of DigitalCommons@University of Nebraska - Lincoln. 


\title{
Synergistic effect of an ultraviolet feeding cue for an avian repellent and protection of agricultural crops
}

\author{
Scott J. Werner*, Shelagh T. DeLiberto, Susan E. Pettit, Anna M. Mangan \\ United States Department of Agriculture, Animal and Plant Health Inspection Service, Wildlife Services, National Wildlife Research \\ Center, 4101 LaPorte Avenue, Fort Collins, CO 80521-2154, USA
}

\section{A R T I C L E I N F O}

\section{Article history:}

Received 21 December 2013

Received in revised form 24 June 2014

Accepted 26 June 2014

Available online 4 July 2014

\section{Keywords:}

Agelaius phoeniceus

Anthraquinone

Chemical repellent

Feeding behavior

Postingestive consequence

Visual cue

\begin{abstract}
A B S T R A C T
Application strategies for avian repellents are needed to maintain efficacious repellent concentrations throughout the period of needed crop protection. We investigated the repellency of an ultraviolet (UV) feeding cue in the absence of postingestive consequences, the combination of the UV feeding cue and an UV-absorbent, postingestive repellent (i.e., a repellent that causes negative postingestive consequences), and a non-UV feeding cue combined with the UV-absorbent, postingestive repellent in red-winged blackbirds (Agelaius phoeniceus). In the absence of negative postingestive consequences, $0.2 \%$ of the UV feeding cue (wt/wt) was not aversive relative to untreated food (i.e., baseline preference test; $P=0.1732$ ). Relative to the repellency of food treated only with the anthraquinone-based repellent, synergistic repellency (i.e., $45-115 \%$ increase) was observed when $0.2 \%$ of the UV feeding cue was combined with $0.02 \%$ or $0.035 \%$ anthraquinone (wt/wt). In contrast, $<10 \%$ repellency was observed for $0.2 \%$ of a non-UV feeding cue (red \#40 aluminum lake dispersion) paired with $0.02 \%$ anthraquinone. Aversion performance was therefore not attributed to characteristics of either conditioned or unconditioned stimuli but their combinations, and enhanced repellency of anthraquinone plus the UV-absorbent cue was attributed to UV wavelengths. Thus, the addition of an UV feeding cue can enhance avian repellency at repellent concentrations realized from previous field applications on agricultural crops (e.g., $\leq 1000 \mathrm{ppm}$ anthraquinone).
\end{abstract}

Published by Elsevier B.V.

\section{Introduction}

The gregarious feeding behavior of some wild birds causes economic losses annually to world-wide agricultural production. For example, red-winged blackbirds (Agelaius phoeniceus; Werner et al., 2008b, 2009), common grackles (Quiscalus quiscula), yellow-headed blackbirds (Xanthocephalus xanthocephalus) and brown-headed cowbirds (Molothrus ater) negatively impact rice (Avery et al., 1997, 1998, 2005; Cummings et al., 2002a,b, 2011; Werner

\footnotetext{
* Corresponding author. Tel.: +1 970266 6136; fax: +1 9702666138 E-mail address: Scott.J.Werner@aphis.usda.gov (S.J. Werner).
}

et al., 2008a, 2010), corn (Carlson et al., 2013) and sunflower (Linz et al., 2011; Werner et al., 2010, 2011) production each year in the United States of America. Cummings et al. (2005) estimated that blackbirds caused approximately $\$ 13.4$ million of damage to USA rice production in 2001. Similarly, blackbird damage to sunflower was estimated to be $\$ 5.4$ million annually in the prime sunflower growing area of North America (i.e., North Dakota, South Dakota, Minnesota; Peer et al., 2003) and \$3.5 million in North Dakota (Klosterman et al., 2013). These losses have motivated the use of several blackbird damage management techniques, including non-lethal behavioral approaches such as chemical repellents. 
The effectiveness and commercial development of blackbird repellents are dependent upon the repellent's efficacy under field conditions, cost relative to expected damages of unmanaged crops, environmental impacts, and food and feed safety (Werner et al., 2008a, 2009). Optimized repellent formulations and application strategies are needed for agricultural crop protection in context of these economic, environmental, and safety thresholds. Thus, much research on repellents for agricultural applications has been focused to investigate the repellency of fungicides and insecticides already registered by the United States Environmental Protection Agency for agricultural applications (Linz et al., 2006; Werner et al., 2008a,b, 2010), and naturally-occurring compounds such as 9,10anthraquinone (Carlson et al., 2013; Cummings et al., 2011; Werner et al., 2009, 2011).

Although anthraquinone is a naturally-occurring substance that was identified as a promising avian repellent in the early 1940s (Heckmanns and Meisenheimer, 1944), no anthraquinone-based repellents are currently registered for agricultural applications in the United States of America. Thus, data regarding efficacy, chemical residues, and application strategies are presently needed for the development of anthraquinone-based repellents and the protection of agricultural crops. Anthraquinone has been used to effectively protect rice seeds and emergent rice seedlings from blackbirds under captive and 2-ha field conditions (Avery et al., 1997, 1998; Cummings et al., 2002a,b, 2011; Neff and Meanley, 1957), turf from Canada goose (Branta canadensis) grazing in captivity (Blackwell et al., 1999; Dolbeer et al., 1998), whole-kernel corn and ripening corn from captive sandhill cranes (Grus canadensis) and blackbirds (Blackwell et al., 2001; Carlson et al., 2013), and sunflower achenes from blackbirds under captive and <0.2-ha field conditions (Werner et al., 2009, 2011). Blackbird repellency was not observed within 2-5 ha rice fields aerially sprayed with 9.3 or 18.6 L Flight Control ${ }^{\circledR}$ / ha (active ingredient [a.i.] 50\% 9,10-anthraquinone, Arkion ${ }^{\circledR}$ Life Sciences, New Castle, DE, USA; Avery et al., 2000a) or within $0.33-0.4$ ha rice fields aerially sprayed with 18.3 or 54.9 L Flight Control $^{\circledR}$ ha $^{-1}$ (Avery et al., 2000b). Anthraquinone residues among these treated rice plots ranged from approximately $175-475 \mathrm{ppm}$ anthraquinone (Avery et al., 2000a) and 275-1000 ppm anthraquinone (Avery et al., 2000b) on the day subsequent to the repellent application. Thus, blackbird repellency under field applications was limited by repellent concentrations realized from previous field applications on agricultural crops (i.e., $>1000$ ppm anthraquinone).

Because field applications of anthraquinone-based repellents have provided $\leq 1000 \mathrm{ppm}$ anthraquinone and the threshold repellent concentration was estimated as $1475 \mathrm{ppm}$ anthraquinone for red-winged blackbirds (Werner et al., 2009), our purpose was to develop an efficacious application strategy for a blackbird repellent at repellent concentrations realized from previous field applications on agricultural crops (i.e., $\leq 1000$ ppm anthraquinone; Avery et al., 2000a,b). Anthraquinone is a cathartic purgative and its action is principally on the large intestine (Merck, 1991); thus, anthraquinone-based repellents cause negative postingestive consequences (i.e., postingestive repellent). Interestingly, anthraquinone also absorbs near-UV wavelengths (Du et al., 1998) that are visible to most birds (i.e., 300-400 nm; Hart and Hunt, 2007). Based upon these biochemical and physical characteristics (i.e., inextricable sensory cue plus postingestive consequence), anthraquinone is a quintessential avoidance conditioning agent for wild birds (Werner et al., 2009) and an effective chemical repellent for the protection of agricultural crops. Indeed, blackbirds conditioned with a UV-absorbent, postingestive repellent (a.i. 50\% 9,10anthraquinone) subsequently avoided food treated only with an UV-absorbent or UV-reflective feeding cue (Werner et al., 2012).

If aversion performance is not determined primarily by the nature of either conditioned or unconditioned stimuli but their combinations (i.e., cue-consequence specificity; Domjan, 1985), and if avian repellency can be optimized by independently varying the concentrations of the UV visual cue and the postingestive consequence, then we predicted that the addition of an UV-absorbent feeding cue can enhance the concentration-response relationship, or efficacy of an UV-absorbent, postingestive repellent for wild birds associated with agricultural depredation. Our objectives were to comparatively investigate the blackbird repellency of (1) an UV feeding cue in the absence of postingestive consequences, (2) the combination of the UV feeding cue and an UV-absorbent, postingestive repellent, and (3) a non-UV feeding cue combined with the UV-absorbent, postingestive repellent.

\section{General methods}

All feeding experiments were conducted in October 2012-February 2013 at the National Wildlife Research Center's (NWRC) outdoor animal research facility in Fort Collins, Colorado (USA). We live-captured 121 male redwinged blackbirds for the experiments. The capture, care, and use of all birds associated with our feeding experiments were approved by the NWRC Animal Care and Use Committee (NWRC Study Protocol QA-1968; S.J. Werner-Study Director).

Blackbirds were maintained in $4.9 \times 2.4 \times 2.4$-m cages (35-45 birds/cage; Werner et al., 2009) within a wire meshsided building for at least 2 weeks prior to the experiments (i.e., quarantine, holding). Free access to grit and a maintenance diet was provided to all birds during quarantine and holding. The maintenance diet included two parts millet: one cracked corn: one milo: one safflower. Blackbird feeding experiments were conducted in visually-isolated, individual cages $(0.9 \times 1.8 \times 0.9 \mathrm{~m})$ within a wire meshsided building. Water was provided ad libitum to all birds throughout the experiments.

An anthraquinone-based repellent (Avipel ${ }^{\circledR}$; Arkion $^{\circledR}$ Life Sciences, New Castle, DE, USA), and titanium dioxide (Evonik Goldschmidt Corporation, Hopewell, VA, USA) and red feeding cues (red \#40, FD\&C aluminum lake dispersion; Roha USA, St. Louis, MO, USA) were used for the feeding experiments. A Genesys ${ }^{\mathrm{TM}} 2,336002$ spectrophotometer (Thermo Spectronic US, Rochester, NY, USA) was previously used to determine that both the Avipel repellent and the titanium dioxide feeding cue absorb near UV 
wavelengths (Werner et al., 2012) that are visible to redwinged blackbirds (Chen et al., 1984; Chen and Goldsmith, 1986). Seed treatments for all experiments were formulated by applying aqueous suspensions $(60 \mathrm{~mL} / \mathrm{kg})$ to whole oilseed sunflower (Ranch-Way Feed Mills, Fort Collins, CO, USA) using a rotating mixer and household spray equipment.

\section{Experiment 1: Baseline preference test of UV feeding cue}

A baseline preference (i.e., choice) feeding experiment was conducted to (1) evaluate blackbird consumption of untreated sunflower seeds versus those treated with the UV feeding cue and (2) identify a numerically preferred concentration of the UV feeding cue for our subsequent feeding experiments.

\subsection{Materials and methods}

Daily sunflower consumption was measured throughout the preference experiment (test days 1-4). Unconsumed sunflower seeds (remaining in each food bowl) and spillage were collected (at 08:00 h, daily) and weighed $( \pm 0.1 \mathrm{~g})$. Weight change (e.g., desiccation) of sunflower seeds was measured daily by weighing seeds offered within a vacant cage throughout the preference experiment.

Eleven red-winged blackbirds (experimentally naïve) were randomly assigned to the baseline preference experiment. All blackbirds were offered untreated sunflower seed ad libitum in two food bowls for 5 days of acclimation in individual cages. Each blackbird was subsequently offered one bowl of untreated sunflower and one bowl of sunflower treated with $0.2 \%$ of the titanium dioxide feeding cue (targeted concentration, wt/wt) at 08:00 h, daily throughout the 4-day test. The north-south placement of food bowls was randomized on the first day and alternated on subsequent days of the experiment.

The dependent measure for the baseline preference experiment was average (i.e., daily) test consumption of treated and untreated sunflower seeds. After successfully conducting Levene's test for equal variances $(\alpha=0.05)$ and affirmatively inspecting the normality of residuals, consumption data were subjected to a repeated measures analysis of variance (ANOVA). The random effect of our model was bird subjects, the between-subjects effect was treatment (treated vs. untreated seed), and the within-subject effect was test day. The treatment effect was analyzed using a mixed model (SAS v9.1). Descriptive statistics $(\bar{x} \pm$ S.E.M.) were used to summarize consumption of treated and untreated seeds throughout the preference experiment.

\subsection{Results}

Relative to average consumption of untreated sunflower, blackbirds non-significantly preferred sunflower treated with $0.2 \%$ of the UV feeding cue $\left(F_{1,10}=2.15\right.$, $P=0.1732$ ). Blackbirds consumed an average of $3.3 \pm 0.4 \mathrm{~g}$ of treated sunflower and $2.5 \pm 0.3 \mathrm{~g}$ of untreated sunflower during the 4-day experiment (Fig. 1). Thus, the UV feeding

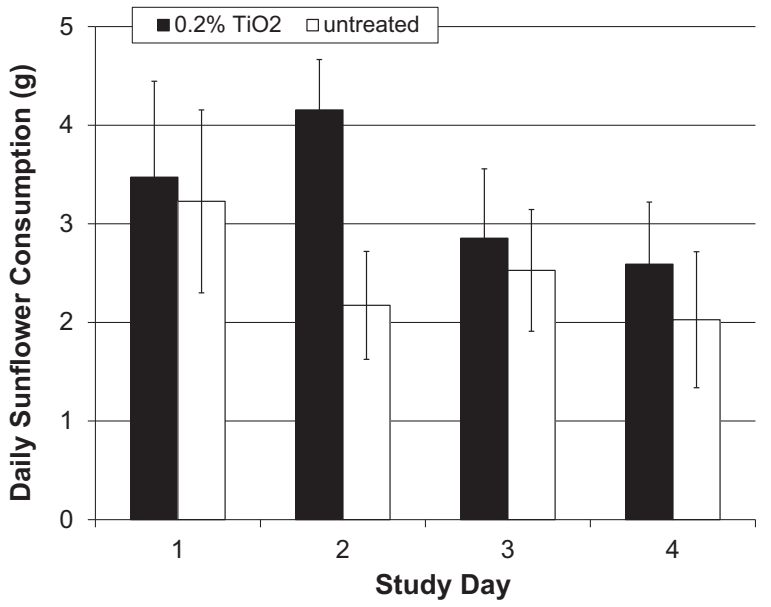

Fig. 1. Mean consumption ( \pm S.E.M.) of oilseed sunflower offered to redwinged blackbirds (Agelaius phoeniceus; $n=11$ ). Blackbirds were offered untreated sunflower and that treated with $0.2 \%$ of an ultraviolet feeding cue (a.i. titanium dioxide, $\mathrm{TiO}_{2}$ ).

cue was not itself aversive (i.e., in the absence of negative postingestive consequences).

\section{Experiment 2: Concentration-response of repellent plus added $U V$ feeding cue}

This experiment was designed to establish a concentration-response relationship of anthraquinone plus $0.2 \%$ titanium dioxide-treated sunflower seeds for blackbirds in captivity. We predicted that (1) the threshold concentration of anthraquinone necessary for blackbird feeding repellency could be reduced by varying the concentration of the anthraquinone-based repellent when combined with the titanium dioxide feeding cue and (2) this optimized anthraquinone concentration would be less than the threshold anthraquinone concentration previously established for red-winged blackbirds offered treated oilseed sunflower seeds (i.e., $1475 \mathrm{ppm}$ anthraquinone; Werner et al., 2009). Daily sunflower consumption was measured throughout the pretreatment and test phases of the experiment as previously described for Experiment 1 (Section 3.1).

We hypothesized that repellency would be directly related to repellent concentration during the repellent concentration-response feeding experiments. We operationally defined laboratory efficacy as $\geq 80 \%$ repellency during captive feeding experiments (Werner et al., 2009, 2011). Thus, we predicted that consumption of efficacious treatments would be $\leq 20 \%$ of pretreatment consumption during the concentration-response experiments.

\subsection{Materials and methods}

Fifty-five red-winged blackbirds (experimentally naïve) were offered untreated sunflower seed ad libitum in one food bowl for 5 days of acclimation in individual cages. Each blackbird was subsequently offered $30 \mathrm{~g}$ of untreated sunflower seeds in one bowl during each of study days 1, 2 and 3. Blackbirds were ranked based upon average 
pretreatment consumption and assigned to one of six treatment groups ( $n=$ nine to 10 birds per group) such that each group was similarly populated with birds that exhibited high-low daily consumption (i.e., observed range of pretreatment food consumption was represented in each test group).

Subsequent to the pretreatment, treatments were randomly assigned among groups $(0.02 \%, 0.035 \%, 0.05 \%, 0.1 \%$, $0.25 \%$, and $0.5 \%$ anthraquinone; targeted concentrations, wt/wt; Werner et al., 2009). Each of these seed treatments also included $0.2 \%$ of the titanium dioxide feeding cue (Werner et al., 2012). We offered $30 \mathrm{~g}$ of treated sunflower seeds in one bowl to all birds on study day 4 , and determined the combined mass $( \pm 0.1 \mathrm{~g})$ of uneaten seeds and seed spillage at 08:00 h on study day 5. A $200 \mathrm{~g}$ sample of each seed treatment was collected for subsequent analysis of actual anthraquinone concentrations ( $\pm 10 \mathrm{ppm}$ anthraquinone) via high performance liquid chromatography (HPLC; Werner et al., 2009, 2011).

The dependent measure for the concentration-response experiments was calculated as test consumption relative to average pretreatment consumption (percent repellency). Non-linear regression procedures (SAS v9.1) were used to analyze repellency as a function of anthraquinone concentration (ppm). Descriptive statistics $(\bar{x} \pm$ S.E.M., $\mathrm{mg}$ anthraquinone/kg body mass) were used to summarize consumption of treated seeds during the concentrationresponse feeding experiments.

\subsection{Results}

We observed a positive concentration-response relationship during the experiment with varying concentrations of the anthraquinone-based repellent and $0.2 \%$ of the UV feeding cue. Blackbirds exhibited $100 \%$ repellency for sunflower treated with $2270 \mathrm{ppm}$ anthraquinone ( $27.4 \pm 13.2 \mathrm{mg}$ anthraquinone/kg body mass) and $0.2 \%$ of the UV feeding cue (Fig. 2). Moreover, compared to the repellency of sunflower treated only with $0.02 \%$ or $0.035 \%$ anthraquinone (i.e., 222 and $556 \mathrm{ppm}$ anthraquinone; lower curve, Fig. 2), the addition of the UV feeding cue in Experiment 2 (upper curve, Fig. 2) caused an 45-115\% increase in blackbird repellency (i.e., $22.8 \%$ to $49.1 \%$ repellency at $166 \mathrm{ppm}$ anthraquinone, and $34.0 \%$ to $49.4 \%$ repellency at $272 \mathrm{ppm}$ anthraquinone). Thus, we observed a synergistic effect of the combined UV feeding cue and anthraquinone-based repellent. With the addition of $0.2 \%$ of the UV feeding cue, blackbird repellency $(y)$ was a function of anthraquinone concentration $(x): y=19.22$ $\ln (x)-57.23\left(r^{2}=0.88, P=0.006\right)$. We therefore predicted a threshold concentration of $1300 \mathrm{ppm}$ anthraquinone (i.e., $80 \%$ repellency) for blackbirds offered sunflower treated with the anthraquinone-based repellent and the UV feeding cue (upper curve, Fig. 2).

\section{Experiment 3: Concentration-response of UV feeding cue}

This experiment was designed to establish a concentration-response relationship of titanium dioxide plus $0.02 \%$ anthraquinone-treated sunflower seeds for

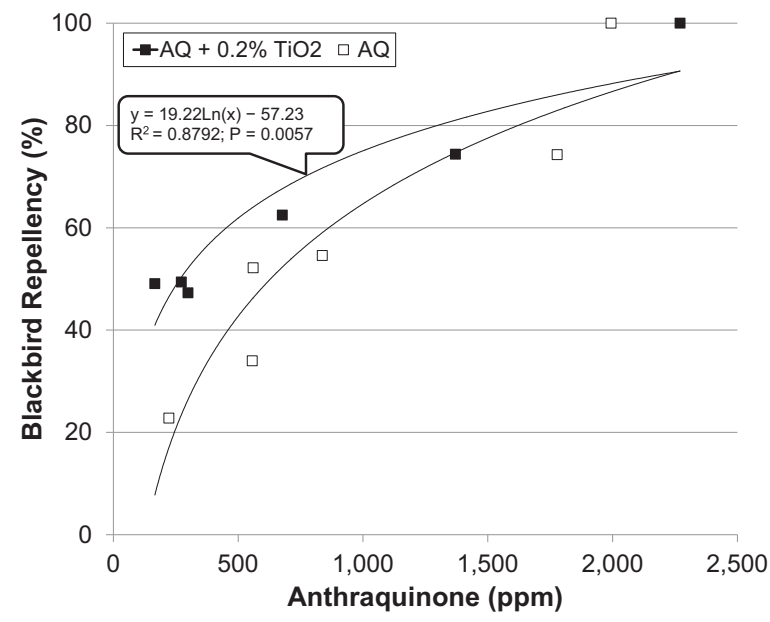

Fig. 2. Mean feeding repellency associated with varying concentrations of an anthraquinone-based repellent (AQ) plus $0.2 \%$ of an ultraviolet feeding cue (a.i. titanium dioxide, $\mathrm{TiO}_{2}$ ) offered to red-winged blackbirds (Agelaius phoeniceus). Repellency represents test consumption relative to average, pretreatment consumption of oilseed sunflower ( $n=$ nine to 10 blackbirds per concentration). Repellency of sunflower treated only with the anthraquinone-based repellent (unfilled squares) is represented from Werner et al. (2009).

blackbirds in captivity. We predicted that the threshold concentration of anthraquinone necessary for blackbird feeding repellency could be minimized by varying the concentration of the titanium dioxide feeding cue. We also predicted that the optimized anthraquinone concentration would be less than the threshold anthraquinone concentration previously established for red-winged blackbirds (Werner et al., 2009).

\subsection{Materials and methods}

The acclimation, pretreatment and test phases of Experiment 2 (Section 4.1) were replicated with 44 experimentally naïve red-winged blackbirds. Treatment groups $1-4$ ( $n=11$ birds/group) received $0.04 \%, 0.08 \%, 0.12 \%$ and $0.16 \%$ (respectively) of the titanium dioxide feeding cue (targeted concentrations, wt/wt). Each of these seed treatments also included $0.02 \%$ anthraquinone (targeted concentration, wt/wt). A $200 \mathrm{~g}$ sample of each seed treatment was collected for subsequent analysis of actual anthraquinone concentrations $( \pm 1 \mathrm{ppm})$ via HPLC. The statistical analyses of Experiment 2 (Section 4.1) were repeated for this concentration-response experiment for the UV feeding cue.

\subsection{Results}

We did not observe a positive concentration-response relationship during the experiment with varying concentrations of the UV feeding cue and $0.02 \%$ of the anthraquinone-based repellent $\left(r^{2}=0.18, P=0.571\right)$. Blackbirds exhibited $<10 \%$ repellency for sunflower treated with $0.04-0.16 \%$ of the UV feeding cue and 164-205 ppm anthraquinone (Fig. 3 ). Thus, $<0.2 \%$ of the UV feeding cue 


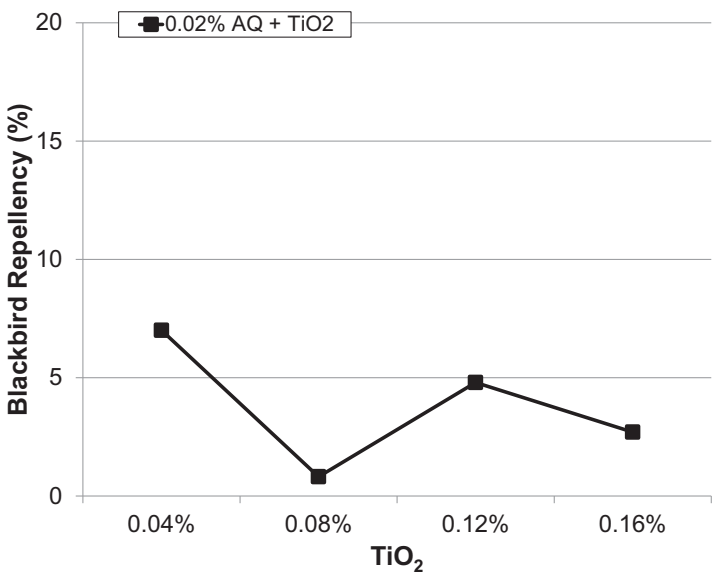

Fig. 3. Mean feeding repellency associated with varying concentrations of an ultraviolet feeding cue (a.i. titanium dioxide, $\mathrm{TiO}_{2}$ ) plus $0.02 \%$ of an anthraquinone-based repellent (AQ) offered to red-winged blackbirds (Agelaius phoeniceus). Repellency represents test consumption relative to average, pretreatment consumption of oilseed sunflower ( $n=11$ blackbirds per concentration).

did not enhance the repellency of anthraquinone-treated sunflower in red-winged blackbirds.

\section{Experiment 4: No-choice test of non-UV feeding cue}

This experiment was designed to evaluate the repellency associated with the combination of the anthraquinone-based repellent and a non-UV feeding cue. This experiment was therefore a crucial test of our hypothesis regarding the cue-consequence specificity (Domjan, 1985) of the UV-absorbent feeding cue and the UV-absorbent, postingestive repellent paired in the previous concentration-response experiments. If enhanced repellency of anthraquinone (i.e., UV absorbent, postingestive repellent) plus the UV-absorbent feeding cue can be attributed to UV wavelengths, then less repellency should be observed for anthraquinone plus visual cues $>400 \mathrm{~nm}$ (e.g., red-treated food).

\subsection{Materials and methods}

The acclimation, pretreatment and test phases of Experiment 2 (Section 4.1) were replicated with 11 experimentally naïve red-winged blackbirds. The test treatment $(n=11)$ included $0.02 \%$ anthraquinone and $0.2 \%$ of red $\# 40$ (Roha USA, St. Louis, MO, USA; Werner et al., 2008c). A $200 \mathrm{~g}$ sample of each seed treatment was collected for subsequent analysis of actual anthraquinone concentrations $( \pm 1 \mathrm{ppm})$ via HPLC.

We again predicted that consumption of efficacious treatments would be $\leq 20 \%$ of pretreatment consumption during the no-choice feeding experiment. Linear regression procedures (SAS v9.1) were used to analyze percent repellency as a function of $0.04-0.16 \%$ of the UV feeding cue (arcsine transformed). Descriptive statistics $(\bar{x} \pm$ S.E.M.) were again used to summarize consumption of treated seeds during the no-choice feeding experiment.

\subsection{Results}

Blackbirds exhibited $4.5 \%$ repellency for sunflower treated with $150 \mathrm{ppm}$ anthraquinone and $0.2 \%$ of red \#40 (i.e., non-UV feeding cue). Compared to the previous concentration-response experiment with varying concentrations of the anthraquinone-based repellent and $0.2 \%$ of the UV feeding cue ( $49 \%$ repellency at $166 \mathrm{ppm}$ anthraquinone; Fig. 2), we observed less repellency of the anthraquinone-based repellent when paired with a nonUV feeding cue. Thus, $0.2 \%$ of the non-UV feeding cue did not enhance repellency of anthraquinone-treated sunflower in red-winged blackbirds.

\section{Discussion}

In the absence of negative postingestive consequences, the UV feeding cue was not aversive during our baseline preference experiment (Experiment 1, Fig. 1). Red-winged blackbirds use affective processes (i.e., flavor-feedback relationships; Provenza, 1995; Provenza and Villalba, 2006) to shift preference for both novel and familiar flavors, and cognitive associations (i.e., visual cue-postingestive feedback) to avoid food, subsequent to toxin exposure (Werner et al., 2008c). Ultraviolet cues alone, however, are unlikely to function as aposematic signals in wild birds (Lyytinen et al., 2001). Indeed, feeding repellents based merely on sensory cues (e.g., flavor, visual cues) are not likely to be effective in the absence of aversive postingestive effects (Provenza, 1997).

Because the addition of $0.2 \%$ of the UV-absorbent cue enhanced the repellency of 166-272 ppm anthraquinone (Experiment 2, Fig. 2), we observed cue-consequence specificity (Domjan, 1985) for visual cues and a postingestive repellent in red-winged blackbirds. Blackbirds cognitively associate pre- and postingestive consequences with visual cues, and reliably integrate visual and gustatory experience with postingestive consequences to procure nutrients and avoid toxins (Werner and Provenza, 2011). These visual cues include UV-absorbent and UV-reflective cues for blackbird feeding behavior (Werner et al., 2012).

Whereas $0.04-0.16 \%$ of the UV-absorbent cue resulted in $<10 \%$ repellency when paired with $164-205 \mathrm{ppm}$ anthraquinone (Experiment 3, Fig. 3), we suggest that $0.2 \%$ is a threshold concentration of titanium dioxide to reliably cue the repellent consequences of the anthraquinone-based repellent (Fig. 2). Unlike 0.04-0.16\% titanium dioxide, we suggest that $0.2 \%$ is a salient cue for anthraquinone repellency, including sub-threshold concentrations of anthraquinone for red-winged blackbirds (i.e., <1475 ppm anthraquinone; Werner et al., 2009). To further test our hypotheses regarding the relationship of the UV feeding cue and the postingestive repellent, we conducted a crucial experiment including a non-UV feeding cue (Experiment 4).

Because the non-UV cue did not enhance the repellency of anthraquinone (i.e., UV-absorbent, postingestive repellent) during the no-choice experiment (Experiment 4), we observed cue-consequence specificity (Domjan, 1985) of a UV feeding cue and a postingestive repellent in red-winged blackbirds (Fig. 2). Moreover, aversion 
performance among our experiments was not determined primarily by the nature of either conditioned or unconditioned stimuli, but their combinations (Domjan, 1985). In addition to the cue-consequence specificity of taste-illness and exteroceptive-peripheral combinations (Domjan, 1985), we suggest that birds reliably associate visual cues with postingestive consequences to avoid food subsequent to toxin exposure (Werner et al., 2008c) and these visual cues include UV feeding cues (Werner et al., 2012). These results have implications for subsequent field applications of chemical repellents and the management of avian depredation.

Our purpose was to develop an efficacious strategy for field applications of an avian repellent and the protection of agricultural crops. In addition to providing sufficient repellent concentrations under field conditions, field efficacy of chemical repellents is constrained by the local overabundance of blackbirds and the assumed daily immigration of repellent-naïve birds within damaged agricultural fields. Interestingly, repellent-naïve birds benefit from repellent-experienced flockmates by learning where to forage for untreated food (Avery, 1994) rather than a socially-facilitated aversion for repellent-treated food. Thus, daily immigration of repellent-naïve blackbirds may not prohibit repellency under field conditions if sufficient repellent concentrations are offered throughout the period of needed protection to some portion of the depredating flock.

The synergistic repellency observed in this study will not instantly maximize the proportion of repellentexperienced flockmates. Rather, the addition of an UV feeding cue can enhance blackbird repellency at repellent concentrations (e.g., <1000 ppm anthraquinone; upper curve, Fig. 2) realized from previous field applications on agricultural crops (Avery et al., 2000a,b). Several chemical repellents and cues exhibit similar UV spectra, and might therefore be used in a field application strategy including an initial application of a repellent and subsequent applications of a visual cue with spectral characteristics sufficiently similar to the repellent (Werner, 2009).

\section{Conclusion}

Whereas the UV feeding cue was not itself aversive (Experiment 1) and the addition of $0.2 \%$ of the UV feeding cue in Experiment 2 increased repellency relative to that observed for anthraquinone alone (Werner et al., 2009), we observed synergistic repellency of the combined UV feeding cue and anthraquinone-based repellent in red-winged blackbirds. Because $<10 \%$ repellency was observed when a non-UV feeding cue was paired with the anthraquinonebased repellent in Experiment 4, enhanced repellency of anthraquinone plus the UV-absorbent cue can be attributed to UV wavelengths. The addition of an UV feeding cue can enhance avian repellency at concentrations realized from previous field applications on agricultural crops (e.g., $<1000$ ppm anthraquinone).

\section{Conflict of interest statement}

None.

\section{Acknowledgements}

This research was supported in part by the National Sunflower Association (Mandan, ND, USA). Our feeding experiments were conducted with Avipel ${ }^{\circledR}$ repellent (Arkion ${ }^{\circledR}$ Life Sciences, New Castle, DE, USA), a titanium dioxide feeding cue (Evonik Goldschmidt Corporation, Hopewell, VA, USA) and red \#40 aluminum lake dispersion (Roha USA, St. Louis, MO, USA). Corporate collaborations do not imply endorsement by the United States Department of Agriculture. The NWRC analytical chemistry unit performed anthraquinone residue analyses for our feeding experiments. We also appreciate the National Wildlife Research Center animal care staff that provided daily care of all birds throughout quarantine and holding for each experiment.

\section{References}

Avery, M.L., 1994. Finding good food and avoiding bad food: does it help to associate with experienced flockmates? Anim. Behav. 48, 1371-1378.

Avery, M.L., Humphrey, J.S., Decker, D.G., 1997. Feeding deterrence of anthraquinone, anthracene, and anthrone to rice-eating birds. J. Wildl. Manage. 61, 1359-1365

Avery, M.L., Humphrey, J.S., Primus, T.M., Decker, D.G., McGrane, A.P., 1998. Anthraquinone protects rice seed from birds. Crop Prot. 17, 225-230.

Avery, M.L., Tillman, E.A., Humphrey, J.S., Cummings, J.L., York, D.L., Davis Jr., J.E., 2000a. Evaluation of overspraying as an alternative to seed treatment for application of Flight Control ${ }^{\circledR}$ bird repellent to newly planted rice. Crop Prot. 19, 225-230.

Avery, M.L., Whisson, D.A., Marcum, D.B., 2000b. Responses of blackbirds to mature wild rice treated with Flight Control bird repellent. Proc. Vert. Pest Control Conf. 19, 26-30.

Avery, M.L., Werner, S.J., Cummings, J.L., Humphrey, J.S., Milleson, M.P., Carlson, J.C., Primus, T.M., Goodall, M.J., 2005. Caffeine for reducing bird damage to newly seeded rice. Crop Prot. 24, 651-657.

Blackwell, B.F., Seamans, T.W., Dolbeer, R.A., 1999. Plant growth regulator (Stronghold ${ }^{\mathrm{TM}}$ ) enhances repellency of anthraquinone formulation (Flight Control $^{\mathrm{TM}}$ ) to Canada geese. J. Wildl. Manage. 63, 1336-1343.

Blackwell, B.F., Helon, D.A., Dolbeer, R.A., 2001. Repelling sandhill cranes from corn: whole-kernel experiments with captive birds. Crop Prot. 20, 65-68.

Carlson, J.C., Tupper, S.K., Werner, S.J., Pettit, S.E., Santer, M.M., Linz, G.M., 2013. Laboratory efficacy of an anthraquinone-based repellent for reducing bird damage to ripening corn. Appl. Anim. Behav. Sci. 145, 26-31.

Chen, D., Goldsmith, T.H., 1986. Four spectral classes of cone in the retinas of birds. J. Comp. Physiol. A: Sens. Neural Behav. Physiol. 159, 473-479.

Chen, D., Collins, J.S., Goldsmith, T.H., 1984. The UV receptor of bird retinas. Science 225, 337-339.

Cummings, J.L., Avery, M.L., Mathre, O., Wilson, E.A., York, D.L., Engeman, R.M., Pochop, P.A., Davis Jr., J.E., 2002a. Field evaluation of Flight Control $^{\mathrm{TM}}$ to reduce blackbird damage to newly planted rice. Wildl. Soc. Bull. 30, 816-820.

Cummings, J.L., Pochop, P.A., Engeman, R.M., Davis Jr., J.E., Primus, T.M., 2002b. Evaluation of Flight Control ${ }^{\circledR}$ to reduce blackbird damage to newly planted rice in Louisiana. Int. Biodeterior. Biodegrad. 49, $169-173$

Cummings, J.L., Shwiff, S.A., Tupper, S.K., 2005. Economic impacts of blackbird damage to the rice industry. Proc. Wildl. Damage Manage. Conf. $11,317-322$

Cummings, J.L., Byrd, R.W., Eddleman, W.R., Engeman, R.M., Tupper, S.K., 2011. Effectiveness of AV-1011 ${ }^{\circledR}$ to reduce damage to drill-planted rice from blackbirds. J. Wildl. Manage. 75, 353-356.

Dolbeer, R.A., Seamans, T.W., Blackwell, B.F., Belant, J.L., 1998. Anthraquinone formulation (Flight Control ${ }^{\mathrm{TM}}$ ) shows promise as avian feeding repellent. J. Wildl. Manage. 62, 1558-1564.

Domjan, M., 1985. Cue-consequence specificity and long-delay learning revisited. Ann. N.Y. Acad. Sci. 443, 54-66.

Du, H., Fuh, R.A., Li, J., Corkan, A., Lindsey, J.S., 1998. PhotochemCAD: a computer aided design and research tool in photochemistry. Photochem. Photobiol. 68, 141-142. 
Hart, N.S., Hunt, D.M., 2007. Avian visual pigments: characteristics, spectral tuning, and evolution. Am. Nat. 169 (Suppl.), S7-S26.

Heckmanns, F., Meisenheimer, M., 1944. Protection of seeds against birds. In: Patent 2,339,335. U.S. Patent Office, Washington, DC.

Klosterman, M.E., Linz, G.M., Slowik, A.A., Homan, H.J., 2013. Comparisons between blackbird damage to corn and sunflower in North Dakota. Crop Prot. 53, 1-5.

Linz, G.M., Homan, H.J., Slowik, A.A., Penry, L.B., 2006. Evaluation of registered pesticides as repellents for reducing blackbird (Icteridae) damage to sunflower. Crop Prot. 25, 842-847.

Linz, G.M., Homan, H.J., Werner, S.J., Hagy, H.M., Bleier, W.J., 2011. Assessment of bird-management strategies to protect sunflower. BioScience 61, 960-970.

Lyytinen, A., Alatalo, R.V., Lindstrom, L., Mappes, J., 2001. Can ultraviolet cues function as aposematic signals? Behav. Ecol. 12, 65-70.

Merck, 1991. In: Fraser, C.M., Bergeron, J.A. (Eds.), Merck Veterinary Manual. , seventh ed. Merck \& Co., Inc., USA, p. 1383.

Neff, J.A., Meanley, B., 1957. Research on Bird Repellents: Bird Repellent Studies in the Eastern Arkansas Rice Fields. Wildl. Res. Lab., Denver, CO, 21 pp.

Peer, B.D., Homan, H.J., Linz, G.M., Bleier, W.J., 2003. Impact of blackbird damage to sunflower: bioenergetic and economic models. Ecol. Appl. $13,248-256$

Provenza, F.D., 1995. Postingestive feedback as an elementary determinant of food preference and intake in ruminants. J. Range Manage. 48, $2-17$.

Provenza, F.D., 1997. Origins of food preference in herbivores. In: Mason, J.R. (Ed.), Repellents in Wildlife Management: Proceedings of a Symposium. National Wildlife Research Center, Fort Collins, CO, pp. 81-90.
Provenza, F.D., Villalba, J.J., 2006. Foraging in domestic vertebrates: linking the internal and external milieu. In: Bels, V.L. (Ed.), Feeding in Domestic Vertebrates: From Structure to Function. CABI, Oxfordshire, pp. 210-240.

Werner, S.J., 2009. Ultraviolet strategy for avian repellency. In: U.S.A. Patent Application No. 12/652,944.

Werner, S.J., Provenza, F.D., 2011. Reconciling sensory cues and varied consequences of avian repellents. Physiol. Behav. 102, 158-163.

Werner, S.J., Cummings, J.L., Pipas, P.A., Tupper, S.K., Byrd, R.W., 2008 a. Registered pesticides and citrus terpenes as blackbird repellents for rice. J. Wildl. Manage. 72, 1863-1868.

Werner, S.J., Cummings, J.L., Tupper, S.K., Goldade, D.A., Beighley, D., 2008b. Blackbird repellency of selected registered pesticides. J. Wildl. Manage. 72, 1007-1011.

Werner, S.J., Kimball, B.A., Provenza, F.D., 2008c. Food color, flavor, and conditioned avoidance among red-winged blackbirds. Physiol. Behav. 93, 110-117.

Werner, S.J., Carlson, J.C., Tupper, S.K., Santer, M.M., Linz, G.M., 2009. Threshold concentrations of an anthraquinone-based repellent for Canada geese, red-winged blackbirds, and ring-necked pheasants. Appl. Anim. Behav. Sci. 121, 190-196.

Werner, S.J., Linz, G.M., Tupper, S.K., Carlson, J.C., 2010. Laboratory efficacy of chemical repellents for reducing blackbird damage in rice and sunflower crops. J Wildl. Manage. 74, 1400-1404.

Werner, S.J., Linz, G.M., Carlson, J.C., Pettit, S.E., Tupper, S.K., Santer, M.M., 2011. Anthraquinone-based bird repellent for sunflower crops. Appl. Anim. Behav. Sci. 129, 162-169.

Werner, S.J., Tupper, S.K., Carlson, J.C., Pettit, S.E., Ellis, J.W., Linz, G.M., 2012. The role of a generalized ultraviolet cue for blackbird food selection. Physiol. Behav. 106, 597-601. 